\section{Canada Food Guide's focus on reducing saturated fat contradicts evidence}

We read the article by Drs. Grant and Jenkins with interest. ${ }^{1}$ We represent a growing group of Canadian physicians and health professionals called the Canadian Clinicians for Therapeutic Nutrition, who use whole food nutritional strategies to prevent and often reverse the burden of chronic noncommunicable disease in our patients. We have been fiercely advocating for evidence-based dietary guidelines to replace the failed low-fat, highcarbohydrate guidelines that were introduced decades ago: guidelines introduced without good evidence, and which have likely shaped the sugarladen, processed-food environment in which we find ourselves. We wholeheartedly agree with ensuring the food industry is not involved in creating new guidelines, or in any front-of-package labelling decisions.

However, we cannot agree that the new Canada's Food Guide (www.canada.ca/ en/health-canada/services/publications/ food-nutrition/evidence-review-dietary -guidance-summary-results-implications -canada-food-guide.html) represents a sufficiently evidence-based approach, as it is largely based on references to existing guidelines that have recently come under high-profile criticism for their lack of a sound scientific base by the National Academies of Sciences, Engineering and Medicine. ${ }^{2}$ We must strongly question making saturated fat a centrepiece of dietary advice, and advocating for low-fat rather than high-fat dairy, both of which run strongly contrary to the balance of available evidence, which has shifted substantially over the last decade.

An analysis of randomized controlled trials ${ }^{3}$ shows there was no evidence to issue the US and UK dietary guidelines on low fat in 1977 and 1983, respectively. Three large, recent observational studies $^{4-6}$ identify dietary carbohydrates as the most consistent culprit in cardiovascular disease and show reduced cardiovascular disease when dietary fat, including saturated fat, is increased. Further, a meta-analysis of 29 prospective cohort studies showed neutral associations between dairy products and cardiovascular and all-cause mortality. ${ }^{7}$

Although we concur that a whole-food, plant-based diet is almost certainly healthier than a standard Western diet, and will reduce disease burden in comparison with that, we are not aware of a single study that has compared a wholefood, plant-based diet with a whole-food, animal protein-based diet. Without these data controlling for food quality, it would be premature to advise Canadians to choose plants over meat. People may choose plant-based patterns if desired, but population-wide guidelines require unequivocal evidence, like that which now exists for sugar. Moreover, plantbased diets must be carefully constructed to include supplementation of the nutrients that are difficult or impossible to obtain when excluding meat products, such as $B_{12}$, absorbable iron, zinc and long-chain n-3 polyunsaturated fatty acids. The potential negative effect of phytoestrogens on children is also a serious concern, and all of these issues are well outlined in a recent publication regarding the concern for safety of a plant-based diet in children. ${ }^{8}$ By giving such advice, we risk repeating the mistakes of the past and risk even more unintended health consequences.

Advocating for reduction of sugar and processed food, and a focus on whole foods, are positions we strongly agree with. We applaud Health Canada for making those suggestions. However, the proposed focus on saturated fat reduction and a plant-based approach are unfounded and contradict the available evidence. This is a matter of considerable concern.

Finally, we note with interest the substantial competing interests of the authors. We absolutely agree that the food industry should not be involved in shaping the Food Guide; our concerns also extend to influence from those industries that would benefit from the wider adoption of a plant-based diet.

\section{Barbra Allen Bradshaw MD}

Anatomical pathologist, Abbotsford

Regional Hospital and Cancer Centre

Abbotsford, BC

\section{Carol Loffelmann MD}

Anesthesiologist, St. Michael's Hospital, Toronto, Ont.

- Cite as: CMAJ 2018 September 4; 190:E1051. doi: 10.1503/cmaj.69753

\section{References}

1. Grant JD, Jenkins DJA. Resisting influence from agri-food industries on Canada's new food guide. CMAJ 2018;190:E451-2.

2. Redesigning the process for establishing the dietary guidelines for Americans. Washington (DC): National Academies of Science, Engineering and Medicine; 2017.

3. Harcombe Z, Baker JS, Cooper SM. al. Evidence from randomised controlled trials did not support the introduction of dietary fat guidelines in 1977 and 1983: a systematic review and meta-analysis. Open Heart 2015;2:e000196.

4. Dehghan M, Mente A, Zhang X, et al.; Prospective Urban Rural Epidemiology (PURE) study investigators. Associations of fats and carbohydrate intake with cardiovascular disease and mortality in 18 countries from five continents (PURE): a prospective cohort study. Lancet 2017;390:2050-62.

5. Grasgruber P, Sebera M, Hrazdira E, et al. Food consumption and the actual statistics of cardiovascular diseases: an epidemiological comparison of 42 European countries. Food Nutr Res 2016;60:31694.

6. Grasgruber P, Cacek J, Hrazdíra E, et al. Global correlates of cardiovascular risk: a comparison of 158 countries. Nutrients 2018;10:E411.

7. Guo J, Astrup A, Lovegrove JA, et al. Milk and dairy consumption and risk of cardiovascular disease and all-cause mortality: dose-response meta-analysis of prospective cohort studies. Eur J Epidemiol 2017; 32:269-87.

8. Cofnas N. Is vegetarianism healthy for children? Crit Rev Food Sci Nutr 2018 Feb. 23 [Epub ahead of print]. doi:10.1080/10408398.2018.1437024.

Competing interests: Barbra Allen Bradshaw and Carol Loffelmann are co-founders of Canadian Clinicians for Therapeutic Nutritition. Barbra Allen Bradshaw eats a whole-food, lower-carbohydrate, omnivore diet. Carol Loffelmann follows a wholefood, low-carbohydrate, gluten-free, omnivore diet. 